Pedagogía y Saberes No. 49

Universidad Pedagógica Nacional

Facultad de Educación. 2018, pp. 201-211

\title{
Educar para el regreso a casa. Vigencia de los ideales humanistas*
}

Artícullo de investigación

Educate for the return at home. Validity of humanist ideas

Educar para o retorno em casa. Vigor das ideias humanistas

Carlos Alberto Ospina $\mathrm{H}^{* *}$

Para citar este artículo:

Ospina, C. (2018). Educar para el regreso a casa. Vigencia de los ideales humanistas. Pedagogía y Saberes, 49, 201-211.

* El presente artículo de reflexión estuvo motivado por temas de discusión en el desarrollo del proyecto de investigación ya desarrollado La cuestión del humanismo en el pensamiento contemporáneo, inscrito en Vicerrectoría de Investigaciones y Postgrados de la Universidad de Caldas con el código 0988610 (2014) a cargo del grupo de Investigación “Filosofía y cultura" (B).

** Profesor titular del departamento de Filosofía de la Universidad de Caldas. Doctor en Filosofía e investigador del grupo Filosofía y Cultura.

Correo electrónico: caos@ucaldas.edu.co

Código ORCID: http://orcid.org/0000-0003-3391-1057 


\title{
Resumen
}

El presente artículo de reflexión propone la necesidad de defender una educación cuyo interés central sea la vida humana y natural en todas sus formas. En él se presenta la evolución de los ideales humanísticos desde el comienzo de la cultura de Occidente, pasando por el mundo clásico, hasta un humanismo contemporáneo. A partir de este rastreo se analiza, por un lado, la doble posibilidad, creadora y destructora del poder humano para configurar tanto el mundo físico como su propia vida; por otro lado, el lugar de los ideales del humanismo en la educación y la necesidad de cultivar, a través de ella, el pensamiento crítico. Se concluye que el humanismo contemporáneo debe estar del lado de las visiones plurales del mundo que favorezcan el devenir de la vida con los demás en espacios donde cada uno pueda actuar y pensar libremente, activando mecanismos inhibidores de la barbarie que anida en cada individuo.

\section{Palabras clave}

autonomía; respeto; tolerancia; desmesura; humanismo

\begin{abstract}
This article of reflection proposes the need to defend an education whose central interest is human life and natural in all its forms. It presents the evolution of humanistic ideals from the beginning of Western culture through the classical world to the contemporary world. Starting from this path, the dual possibility, creative and destructive of human power, is analyzed, on the one hand, to configure the physical world for its own life; on the other hand, the place of the ideals of humanism in education and the need to cultivate, through it, critical thinking. It is concluded that contemporary humanism must be on the side of the world's plural visions that protect life from becoming with others in spaces where each one can act and think freely, activating mechanisms that inhibit the barbarism that nestles in each individual.
\end{abstract}

\section{Keywords}

autonomy; respect; tolerance; untampered; humanisms

\section{Resumo}

O presente artigo de reflexão propõe a necessidade de defender uma educação cujo interesse central seja a vida humana e natural em todas as suas formas. Nele se apresenta a evolução dos ideais humanísticos desde o começo da cultura Ocidental passando pelo mundo clássico até o mundo contemporâneo. Partindo deste percurso se analisa, de uma parte, a dupla possibilidade, criadora e destrutora do poder humano para configurar o mundo físico quanto a sua própria vida; de uma outra parte, o lugar dos ideais do humanismo na educação e a necessidade de cultivar, através dela, o pensamento crítico. Conclui-se que o humanismo contemporâneo deve estar do lada das visões plurais do mundo que protejam o devir da vida com os outros em espaços onde cada um possa agir e pensar livremente, ativando mecanismos inibidores da barbárie que aninha em cada indivíduo.

\section{Palavras-chave}

autonomia; respeito; tolerância; desmesura; humanismo 


\section{Un comienzo perturbador y conflictivo}

El conflicto es una condición consustancial al carácter humano, como muy bien lo entendieron los griegos. Aunque no solo entre los hombres, porque desde la primera generación de sus dioses el antagonismo y la disputa también estuvieron presentes. Si fue así entre los dioses, con mayor razón en la comunidad humana, inicialmente surgida de la tierra, hasta el punto de que se habla de una generación de hombres, guerrera y salvaje, "de la época de bronce", cuyos miembros se aniquilaron entre sí hasta el último de ellos. Antes, otra generación, "la de plata", había desaparecido exterminada por Zeus por haberse negado a ofrecerle sacrificios. El nuevo comienzo es el que conocemos como la generación de Prometeo, quien formó los hombres de las cenizas que quedaron de los titanes cuando terminaron derrotados por Zeus. Pero Prometeo forma los hombres rivalizando, a la vez, con los dioses olímpicos a quienes les arrebató el secreto de las artes y el fuego para dárselos a los mortales, quienes sin él no hubiesen podido sobrevivir. Prometeo, el primer protector de lo humano, creyó además hacerle un gran favor al hombre encerrando en una caja todos los males que como mortal podrían aquejarle: las enfermedades, el dolor, la locura, los vicios, las pasiones, el deterioro físico y la muerte. Pero Zeus implacable envió a Pandora, quien dejó escapar todos los males y los esparció por el mundo; en el fondo solo quedó, como sabemos, la esperanza. Esta por lo menos liberó a los hombres del impulso de ponerles fin a sus días ante la magnitud de los males que les llegaron.

Según otra versión, los hombres se acurrucaron pasivamente en la penumbra de sus cuevas, ya que conocían la hora de su muerte. Entonces Prometeo les concedió el olvido. Desde ese momento supieron que habían de morir, pero desconocían cuándo. Y se encendió en ellos el afán de trabajo, al que Prometeo dio nuevo aliento con el don del fuego. (Safranski, 2010, pp. 20-21).

Según vemos, el hombre originariamente fue una criatura sin conciencia de lo que ella misma era, ni de los males que como mortal le pertenecían, por lo que se sentía inmortal. La misma imagen nos ofrece el mito del paraíso terrenal. Cuando en virtud y consecuencia del pecado original se hizo consciente de que podía morir y de que era una criatura expuesta a muchos peligros y riesgos, fue igualmente cuando surgió la libertad; la de decir no a las prohibiciones que se le hacían, porque toda prohibición, paradójicamente, constituye una invitación. Al rebelarse el hombre, al decir no a lo prohibido, despertó el dolor originario de la conciencia y, a la vez, la posibilidad de percibirse a sí mismo, de reflexionar acerca de lo que él era, porque hasta entonces solo se había mantenido encerrado e inocente en su propio cuerpo e invisible para sí mismo.

El hombre estaba habituado a vivir en un mundo donde no tenía necesidades, o al menos no las sentía, porque era una vida sin sobresaltos y en armonía con el entorno natural. Todo lo que aprendía lo incorporaba mecánicamente a su modo de responder a los estímulos del mundo, de tal manera que la acción habitual hecha maquinalmente transcurría sin conciencia, sobre todo porque disponía de lo necesario para vivir y la suya era una vida sumergida en la acción. Bergson fue uno de los primeros pensadores en defender el hecho de que más originaria que la teoría es la práctica y que la acción precede al pensamiento. Sin embargo, no se trata de los actos habituales y mecánicos per se, porque resulta poco sostenible suponer una existencia inocente y despreocupada, como la de la criatura sin conciencia que era el hombre en el paraíso y quien se debía solo a sí mismo, en unidad plena con la naturaleza, lo cual también haría suponer la existencia de una vida imperturbable. Esta resulta tan inconcebible como el puro actuar mecánico, dado que por lo general la acción encuentra obstáculos para alcanzar su fin y solo cuando "el cumplimiento del acto es detenido u obstaculizado, puede surgir la conciencia" (Bergson, 1963, p. 562). Vale decir, cuando actuamos en el mundo al mismo tiempo nos vamos percatando de él y de las cosas en la medida en que él y ellas se vuelven problemáticos y ofrecen resistencia a nuestros deseos y querencias, forzándonos a pensar en salidas, bien sea creando herramientas y artificios o dirigiendo la acción, por instinto o por inteligencia, hacia otros caminos alternativos. Ello configura, en general, la comprensión natural del mundo (cfr. Bergson, 1963, pp. 558-559).

Para Bolnow (2001), por su parte, la idea de Bergson de que la conducta actuante es la fuente originaria del intelecto, que surge cuando el curso habitual de la acción se ve obstaculizado, se relaciona estrechamente con la concepción de Dewey de que el hábito es el trasfondo que sostiene el todo de la vida, por lo tanto para ambos autores lo primero en el ser humano no es el instinto ni las impresiones sensoriales puras, y mucho menos la teoría. Lo originario en uno es la acción y en Dewey es el hábito, concepto básico y decisivo que este entiende como una comprensión adquirida que se muestra en el actuar; pero acción y hábito son el origen de la conciencia y el pensamiento cuando son perturbados. Solo cuando el curso habitual de la acción tropieza con obstáculos o es trastornado opera el intelecto, la conciencia. 
En consecuencia, el instinto y el pensamiento emergen simultáneamente, y no cuando la vida transcurre plácidamente en su hábito, sino cuando se presenta un obstáculo. La ruptura del hábito; por lo tanto, la carencia y no la abundancia, la falta y no un estado de serenidad imperturbada: he ahí el origen de la conciencia. (Bolnow, 2001, p. 49).

La esencia de la vida es la perturbación y el desasosiego, por eso "la vida sana y armónica no piensa porque no necesita hacerlo" (Bolnow, 2001, p. 49); así, la toma de conciencia significó romper con la vida paradisiaca y despreocupada que según las narraciones míticas era la de los primeros hombres.

Al tomar conciencia el hombre se separó de sí mismo y se rompió la unidad originaria con la naturaleza, cuando vio que en lugar de un solo ser, el suyo propio, también existía otra cosa, la conciencia, por eso ésta la experimenta con dolor. Con ella se percató de sí mismo y además conoció de la presencia del mundo como lo otro diferente que a cada instante trastorna su existencia.

\section{La ampliación del mundo}

Con la toma de conciencia el mundo humano se amplió hacia la dimensión espiritual y con ella también se despertó el anhelo y el deseo del hombre de ir siempre más allá de los límites, todo lo cual rebasó su mero estar sumergido entre las cosas materiales y en el fondo biológico y animal. De Prometeo aprendió las artes y la pericia para enfrentar la vida; y por medio de lo que le fue prohibido en su estancia en el paraíso conoció, incluso antes de cometer pecado, la diferencia entre algo bueno y algo malo. Vale decir, la irrupción de la conciencia perceptiva (y aperceptiva) también significó la revelación de la conciencia moral. Si había algo proscrito, la prohibición misma le dio a conocer al hombre - criatura todavía inocente-que había algo "malo" de lo cual alejarse y a lo que debía decir no. Y fue justamente esa posibilidad de decir no la que dio comienzo a la aventura de la libertad; pero en este caso, de decir no a la prohibición en lugar de a lo prohibido. Cuando ello ocurrió tomó conciencia de lo que él era; significó que por primera vez, desde la conciencia, se hizo visible para sí mismo, pudo verse desnudo y fue capaz de reflexionar sobre sí mismo. Sintió, entonces, haber cometido una falta, porque siguió abierta la opción que no escogió, la de poder atender a la prohibición y decirle sí. Esa posibilidad abierta de decir no o sí, es libertad. Así que la conciencia no es solamente un modo de conocimiento, es también un modo de libertad (cfr. Safransky, 2010, pp. 21-25), en virtud del cual los seres humanos somos lanzados a lo abierto y así no terminamos confinados a una sola manera de ser, sino que tenemos que ir produciendo, por medio de nuestra espontaneidad, un nuevo ser impredecible cada vez, y así también ir haciendo manifiesta la capacidad de poder comenzar de nuevo a cada instante. "Podemos y debemos actuar; y con nuestras acciones dejar que se despliegue el ser, ya sea hacia el bien o hacia el mal" (cfr. Safransky, 2013, p. 32).

La conciencia, por lo tanto, nos separa de nosotros mismos, pero también de la naturaleza y del mundo, por lo que abre un ámbito de posibilidades (que la tradición llama trascendente) hasta ahora desconocido, que tendremos que ir moldeando con la imaginación a la medida de lo que queremos hacer de nuestro mundo y de lo que nosotros mismos deseamos ser ${ }^{1}$. Todo ello depende de la elección que tomemos, de lo que libremente decidamos hacer para lo bueno o lo malo.

De ahí que el poeta trágico Sófocles, en el siglo $\mathrm{V}$ a. C., al hablar del hombre dijo que "poseyendo una habilidad superior a lo que se puede uno imaginar, la destreza para ingeniar recursos, la encamina unas veces al mal, otras veces al bien" (Sófocles, 365, 2006, p. 150). Esta opción es posible porque cuenta con la libertad para hacer lo uno o lo otro; y quizás sea el hecho de disponer de ambas posibilidades abiertas para su elección lo que da origen a la permanente desazón en que se mantiene. Sófocles ya había afirmado antes que "muchas cosas asombrosas existen y, con todo, nada más asombroso que el hombre" (330, 2006, p. 149) porque en general, para los griegos, dicho igualmente por sus poetas épicos y trágicos, el hombre es un ser prodigioso y terrible, capaz de hazañas muy grandes, pero también de las mayores maldades, desafueros y tropelías, hasta el punto de que cualquiera, equivocadamente, pensaría que solo a los poetas les cabe imaginar.

Sin embargo, los griegos consideraban que quienes además de hacer el mal también podían consagrarse al cultivo de las virtudes, la belleza y la bondad eran los integrantes de comunidades que se reconocen como

1 Este es quizás el alcance de las palabras del poeta cuando afirma que "poéticamente habita el hombre sobre la tierra" (Hölderlin) y que numerosos pensadores no han dejado de señalar de muy diversas maneras. Safranski, por ejemplo, lo expresa en muchos pasajes de una de sus obras dedicada a mostrar muy distintos esfuerzos del hombre por ir camino a la casa de su ser: "Es un convencimiento interior que resulta imposible basar en otra cosa que no sea la arrebatadora imaginación poética. Se trata de la sencilla y a la par enigmática experiencia de crear realidades en el interior que no pierdan su carácter de realidad internamente vivida a pesar de corresponderse poco o nada con el exterior. De ahí que Kleist definiera en una ocasión la poesía como 'arte divino'”. (Safranski, 2013, pp. 53-54). "Esta vida del espíritu es experimentada como extraordinariamente real, y sin embargo, invisible por ser incorpórea, aunque precisamente por eso, libre de los límites de lo corpóreo" (p. 103). 
de origen o de un lugar común, de la polis, porque los extranjeros, los de lengua extraña, los bárbaros, sin lugar a dudas no tienen otra opción constitutiva que dedicarse a la maldad. Vale decir, el único que merecía ser tratado y respetado como humano era el habitante de la polis, como quien podía ponerse por encima de las determinaciones naturales, aunque consciente de que jamás dejaría de llevar en sí las fuerzas terribles, dionisiacas dirá Nietzsche, de la naturaleza.

El hombre es poderoso, por su capacidad para hacer cosas, pero a la vez temible y espantoso porque con su temeridad atrae sobre sí el castigo de los dioses. Esa doble condición y la necesidad de conservar la existencia, exige desarrollar sobre todo la capacidad de resistir los impulsos y sobrepasar la dimensión puramente animal e instintiva. Justamente así han surgido las distintas culturas, como ocurrió entre los griegos, quienes con sus mitos, la filosofía, la política, el arte y las técnicas construyeron un ámbito intermedio entre la realidad y el hombre y de esa manera pudieron atenuar o mantener en sus límites los impulsos naturales, cuya manifestación se torna destructiva y violenta cada vez que el individuo no contiene esas fuerzas. El mundo natural, el de las cosas dadas en la naturaleza, solo como realidad física y material, el que según el mito religioso los primeros padres encontraron en el paraíso, no es el mundo humano, porque el verdadero ámbito humano se abre con las creaciones de la fantasía y la imaginación, que son además el espacio para el ejercicio de la libertad creadora. En palabras de Cassirer:

... el hombre ya no vive solamente en un puro universo físico sino en un universo simbólico. El lenguaje, el mito, el arte y la religión constituyen partes de este universo, forman los diversos hilos que tejen la red simbólica, la urdimbre complicada de la experiencia humana. [...] Todo progreso en pensamiento y experiencia afina y refuerza esta red [...] En lugar de tratar con las cosas mismas, en cierto sentido, conversa constantemente consigo mismo. Se ha envuelto en formas lingüísticas, en imágenes artísticas, en símbolos míticos o en ritos religiosos, en tal forma que no puede ver o conocer nada sino a través de la interposición de este medio artificial. Su situación es la misma en la esfera teórica que en la práctica. Tampoco en ésta vive en un mundo de crudos hechos o a tenor de sus necesidades y deseos inmediatos. Vive, más bien, en medio de emociones, esperanzas y temores, ilusiones y desilusiones imaginarias, en medio de sus fantasías y de sus sueños. "Lo que perturba y alarma al hombre - dice Epicteto-, no son las cosas sino sus opiniones y figuraciones sobre las cosas". (Cassirer, 1968, pp. 47- 48).
Por ello mismo, según este autor, identificar el lenguaje con la razón es tomar la parte por el todo (pars pro toto), porque además de un lenguaje conceptual tenemos uno emotivo; junto al lenguaje lógico y científico, tenemos el lenguaje poético e, incluso, antes de que el lenguaje exprese pensamientos, expresa sentimientos y emociones. Por eso la noción de razón resulta inapropiada para abarcar toda la riqueza y diversidad de las formas de vida cultural humana, que son formas simbólicas como caminos abiertos a la civilización. De ahí que Cassirer proponga su famoso giro al definir al hombre como animal simbólico, en lugar de la tradicional definición como animal racional (cfr. Cassirer, 1968, p. 49).

El lenguaje es el sistema simbólico por excelencia porque a cambio de dirigirse directamente a la realidad material, apunta a un mundo independiente, el mundo mental, imaginado, fantaseado, conformado de significados y de sentidos, que es el mundo que habitamos los humanos. El lenguaje, como sistema de símbolos, es la manera humana de comprender y participar con los demás de las vicisitudes del mundo. Por esto el valor de la educación se pierde y empobrece cuando la reducimos a una relación virtual (a distancia), dado que su fortaleza radica en que el aprendizaje de los sistemas simbólicos necesarios para comprender nuestro mundo y nosotros mismos requiere de la cooperación de otros individuos capaces de ello, de nuestros semejantes con quienes compartimos juegos, experiencias y la vida en todos sus aspectos, o del maestro o del experto. La paideia griega era eso, la enseñanza de un estilo de vida, de una forma de ser individual y colectiva que transmitían las ideas de virtud, belleza, bondad, justicia, formuladas en el pensamiento filosófico, en el decir poético, en la creación artística, en la leyenda mítica y en los enunciados de normas y leyes materializadas, a la vez, en sus instituciones y en sus formas concretas de organizar la vida de la polis.

La vigencia de esos mundos simbólicos, su revitalización y valor para la vida los otorga el trato con los demás, porque el encuentro con los otros es lo que en verdad enseña y nos forja como humanos. Es en virtud de ello que se nos abre el sendero de acceso al mundo simbólico, donde permanecemos los seres humanos en nuestro paso por la existencia. De las cosas y procesos que están en el mundo objetivo, puestos frente a nuestros ojos, podemos aprender con la experiencia directa, pero lo que ellos "significan" para nosotros es imposible sin la cooperación de los demás. Además, al tomar conciencia de la existencia de los otros también entramos en el mundo de la moral, porque en nuestro trato con ellos nos damos cuenta de que se les puede hacer bien o mal, 
nociones que solo tienen sentido en las relaciones entre individuos. De esta manera también entramos en el mundo de la libertad, porque al actuar bien o mal lo hacemos porque estamos eligiendo entre las distintas alternativas abiertas por una cultura y un lenguaje compartido con los demás.

\section{El humanismo clásico}

El hecho es que nos hicimos conscientes de nuestra precariedad, de los males constitutivos que nos acompañan, de nuestra finitud, pero también de nuestra peculiar capacidad de crear y habitar ámbitos simbólicos como si fuesen espejos nuestros, vale decir, los productos de la cultura mediante los cuales miramos y transformamos la realidad y nosotros mismos. Esta gran capacidad, este enorme poder de crear y transformar, alimenta también nuestra desmesura, la misma que nos lleva a toda forma de temeridad, hasta el punto de usarla permanentemente contra los otros o para negar lo que somos, para renegar de nuestra precaria condición, inventando un más allá perfecto, de suprema pureza y bondad. Cuando llegamos a lo último la condición humana quedó fijada a una forma definida, a la bondad que a toda costa es preciso conservar, igual que a la absoluta dependencia de la autoridad divina.

El manto del olvido que Prometeo nos entregó para caminar sin el agobio de la amenaza de la muerte, también lo tendimos durante la Edad Media sobre nuestras imperfecciones constitutivas, y alimentamos el recuerdo de que solo somos criaturas bondadosas, cuya mayor responsabilidad es conservarnos como tales. Por eso desde el comienzo jamás deja de acompañarnos un agobiante sentimiento de culpa por haber caído en la falta original y cada vez que nos perdemos y nos hundimos en el mal; entonces, para la concepción medieval del mundo únicamente existía Dios como salida y la salvación que ese ser ofrecía, la cual está en su reino, que no es de este mundo. El hombre, por lo tanto, valía en relación con Dios, por ser su criatura; así también su educación y formación dependían de la autoridad de la Iglesia como depositaria de la palabra divina, que era la única posible de ser escuchada.

Con la introducción de las religiones monoteístas se rompió la relación del hombre con sus universos simbólicos y, con ellos, los significados que les otorgaba o encontraba en sus acciones, en las cosas de su mundo y las maneras de ordenarlo, para ir hacia el estrecho y fijo significado de un único y absoluto orden, el orden divino. Contra ello reaccionó el humanismo del Renacimiento cuando retornó a los textos griegos como fuente de formación y no de simple veneración histórica; por eso durante el siglo XIV se adoptó la palabra humanitas, que muchos siglos atrás había usado Cicerón (siglo I a. C.) para traducir la noción de la paideia griega.

El término humanista señala a alguien dedicado a las letras - a las humanidades, se dice-, pero en realidad la mirada a los textos clásicos no se hizo en sentido erudito sino como la fuente en la que las gentes del Renacimiento se asomaron para ver otras historias, otros ideales de vida y otras existencias. De esta manera fue posible recuperar la imagen del hombre como un ser frente a posibilidades abiertas y libre de elegir entre ellas, como sucede con el bien o el mal. El conocimiento adquirido mediante la experiencia y a través de relatos, historias y nociones es el instrumento para luchar contra el riesgo de que se desate en el individuo la barbarie que anida en sus entrañas y animarlo más bien al cultivo del impulso creador que también lo acompaña y gracias al cual puede dar forma a lo que aún no tiene orden ni figura, como su propia vida. Por ello sus empresas, la belleza y el conocimiento adquirieron valor universal, que es el valor de la cultura compartido por todos como un apreciable rasgo común.

El humanismo surgió como el intento por dignificar al hombre (de ahí el título del célebre discurso de Pico della Mirandola — siglo xv-Sobre la dignidad del hombre), lo cual significó liberarlo de la autoridad de la Iglesia y hacer de él un ser autónomo de cualquier poder diferente al suyo propio. Este pensador en realidad ve al hombre como una de las más admirables criaturas, porque no posee una forma definida y propia, vale decir, justamente por lo mismo que Sófocles y los poetas griegos encontraron de asombroso en él, por su naturaleza dinámica, "indefinida" y por su gran poder de adquirir la forma que desee.

No te he hecho ni celeste ni terreno, ni mortal ni inmortal, con el fin de que tú, como árbitro y soberano artífice de ti mismo, te informases y plasmases en la obra que prefirieses. Podrás degenerar en los seres inferiores que son las bestias, podrás regenerarte, según tu ánimo, en las realidades superiores que son divinas. (Della Mirandola, 2006, p. 5)².

2 Y agrega “¿Quién no admirará a este camaleón nuestro? 0, más bien, ¿quién admirará más cualquier otra cosa? No se equivoca Asclepio el ateniense - en razón del aspecto cambiante y de esta naturaleza que se transforma incluso a sí misma - cuando dice que en los misterios el hombre era simbolizado por Proteo" (Della Mirandola, p. 6). “¿Quién, pues, no admirará al hombre? A ese hombre, [...] precisamente porque se forja, modela y transforma a sí mismo según el aspecto de todo ser y su ingenio según la naturaleza de toda criatura. [...] Pero ¿para qué destacar todo esto? Pues para que comprendamos, ya que hemos nacido en la condición de ser lo que queramos, que nuestro deber es cuidar de todo esto: que no se diga de nosotros que, siendo en grado tan alto, no nos hemos dado 
Se le atribuye así al hombre un papel mucho más importante que el que desempeñaba en la cultura cristiana, porque vuelve a ser la fuente y el fin de sus actos, pensamientos y de sus propias realizaciones, con todas las vicisitudes que tenga que afrontar en la existencia aquí en la tierra. Los asuntos humanos quedaron en manos de los humanistas, mientras que los divinos en la de los teólogos, razón por la cual el humanismo se convierte en un asunto completamente laico.

El humanismo renacentista develó algo que estuvo presente desde los griegos: la facultad inherente al hombre de configurar lo que carece de forma, y tal facultad es poder, pura potencia interna de la vida cuando lucha por seguir viva, lo que, como dijimos, fácilmente puede ser también fuerza destructiva. La tiranía del teocentrismo ocultó esa doble constitución, creadora y destructora, para defender la imagen del hombre como un ser "pecador", cuyo único destino es reincorporarse al camino del bien, asumiendo incluso las penitencias y castigos que merezca por no hacerlo. Pero la vida humana es una lucha permanente por oponer a todos los poderes destructivos, externos e internos, la capacidad que tenemos los individuos de ir al encuentro de aquello que queremos y aspiramos ser, como potencia creadora para la conformación y como facultad de realización propia. Por eso el humanismo en todo momento ve la dignidad del hombre como la libertad de elegir entre distintas formas de ser, con preferencia aquellas que contribuyan mejor a construir los ámbitos que favorezcan el devenir humano, y donde cada persona pueda actuar y pensar sin ningún tipo de tutelaje tiránico, humano o divino.

\section{¿Qué es el hombre?}

Sócrates: entonces, ¿qué es el ser humano? Alcibíades: no sé qué contestar.

Platón, Alcibíades, I, 129a

No se puede pasar por alto que al hablar de una concepción humanista nos encontramos con dos posiciones en discusión desde Grecia, una que trata de otorgarle al ser humano una esencia y forma establecida y otra posición para la que él es el artífice

cuenta de habernos vuelto semejantes a los brutos y a las estúpidas bestias de labor" (pp. 7-8). Todo ello indica que al hombre no se le puede atribuir una esencia inmutable, sino que, precisamente, su esencia es el cambio y la transformación; de ahí la comparación con un camaleón o con Proteo, el más famoso entre los dioses capaces de metamorfosearse en diversos seres. de sus propios modos de ser. Platón, por ejemplo, quien es partidario de la primera, consideraba que las transformaciones de algunos dioses, como Proteo -narradas por los poetas-, no correspondían con la verdadera naturaleza de lo divino (República, $381,1998)$ porque "el dios es simple y es, en todos los seres, quien menos puede abandonar su propio aspecto" (República, 380d, 1998, p. 93), sobre todo porque siendo perfecto cualquier cambio no podría ser hacia algo mejor y terminaría, más bien, por incorporar en él una imperfección. Es justo por ser invariable, y no por su aspecto cambiante, lo que para Platón lo divino constituye el modelo inamovible que el hombre debe perseguir y consiste en realizar su esencia, vale decir, el puro pensamiento racional, lo más divino que el ser humano pueda tener. Frente a esa concepción esencialista, radicalizada al extremo por el cristianismo, se da la propuesta dinámica de Pico della Mirandola y el humanismo renacentista, que en gran medida está más cerca de los griegos cuando abordan la vida práctica y no la teórica. Es el caso, por ejemplo, de Aristóteles, quien asume la praxis humana, mediante la vida racional activa, como la más rotunda realidad de la existencia tal como transcurre cotidianamente con los otros en la familia, con "los amigos y conciudadanos, puesto que el hombre es un ser social" (Aristóteles, 1997, 1097b, 5-10, p. 22), hecho para vivir en la polis, en una ciudad, componente central de la felicidad, porque quien "vive una vida solitaria" es desgraciado ${ }^{3}$.

Justamente por el continuo trato con los demás, el ser humano se va forjando un modo de ser a la medida de las exigencias de la vida en sociedad, y esta puede hacerse agobiante o gratificante de acuerdo con las decisiones que cada persona toma o por las que asumen los demás. Sin embargo, las decisiones, que deben ser libres, también están determinadas por el carácter que uno mismo se haya formado. De ahí la insistencia de los griegos en el cultivo y la práctica de las virtudes para ese fin. Ellos llaman ethos al carácter que cada uno de nosotros habita, nuestra humanitas o nuestra casa, situada en el reino temporal de este mundo, donde el hombre vive y participa de multitud de modos de ser diferentes. Y fue un logro de la época moderna acoger la autonomía humanista y la potencia, el poder humano, para mostrar que la búsqueda de la verdad y el conocimiento del mundo se pueden conseguir con independencia de lo que la tradición y la autoridad imponen mediante la experiencia y la razón. En todo caso, no somos inquilinos de un más allá intemporal, pero ello no significa que nos

3 En la Política (I 2, 1253a 2-3) Aristóteles afirma que el hombre es un "animal político", vale decir, es un animal social que vive en la polis. 
neguemos a aceptar un orden ideal y trascendente, como obra del propio hombre, y no como si fuese una realidad ontológica hacia donde estamos obligados a dirigirnos.

Ya se dijo que gracias al lenguaje podemos referirnos a la realidad que nos determina, pero también a los objetos y universos simbólicos en que nos reconocemos y nos definimos. Aprovechando entonces esa capacidad, la modernidad triunfante creó el mito de que el uso metódico de la razón, como entendimiento calculatorio, nos da esperanzas de ir progresivamente hacia el logro de una mejor vida. Aunque esa meta la sitúa en la tierra, y ya no en el más allá como hizo la religión, el problema radica en que cambia un absoluto por otro, por la idea de progreso y de un futuro mejor, en el cual se supone que el hombre se emancipará de toda dominación; un futuro que, tomado como punto de comparación, hace ver el presente como insoportable. Lo cierto es que con la promesa de un futuro mejor, la esperanza adquiere mayor protagonismo que el propio transcurrir de la existencia presente y los males del mundo, como si importara muy poco tener que soportarlos frente al supremo valor otorgado a las metas finales y la prometida dicha futura. Sin embargo, la historia está llena de ejemplos terribles del dolor, destrucción y muerte que causan los salvadores de la humanidad a nombre de ideales únicos y absolutos, que ellos suponen que encarnan.

Por otro lado, la fascinación que produjeron los resultados de la ciencia y la técnica también despertó en el hombre el orgullo ante el propio poder y revivió la tentación de la desmesura que vimos en las primeras generaciones de hombres, cuando se atrevieron a desafiar a los dioses, aunque siempre terminaron aniquilados o desolados porque así atraían el castigo divino. Y esta vez la tentación fue tan grande que, olvidándose de los castigos, el humanismo ilustrado, antropocéntrico, cayó en la desmesura del poder de la razón, y como si hubiese sido la esperanza escondida en el fondo de la caja de Pandora, defendió la idea de que con su uso metódico nos liberaríamos de la tiranía divina y todo, por fin, iría bien.

Pero el hombre cuenta con el talento de ponerle límites a la razón calculatoria, sin destruirla porque indudablemente es una facultad humana de primer orden, concibiendo ideales de vida que hablan tanto a las capacidades racionales, como a las de la sensibilidad, por lo que no se trata de ideales religiosos resultado de la fe, ni ideales del conocimiento como las utopías científicas o las visiones del mundo "correctas" o abstractas para imponérselas a todos. "Un ideal, un valor, jamás podrá ser verdadero (o falso), sólo es más o menos elevado" (Todorov, 2003, p. 176), en la medida en que sea capaz de ponerle medida a la desmesura humana.

Max Weber habla, en El político y el científico (1995, pp. 223-224), de algo así como un "politeísmo de los valores" o una "eterna lucha entre dioses" para mostrar que es imposible escoger entre distintos sistemas de valores con el fin de imponer uno solo como el verdadero o el más racional. Se trata de preferir los valores que, de darse, todos podamos compartir y puedan hacerse universales, aun como aspiración, en lugar de inclinarnos hacia los valores considerados "más racionales". Por ejemplo, la paz y no la guerra, porque todos podemos vivir en paz, mientras que en la guerra impera la desmesura y siempre habrá vencidos. Nunca faltan los que prefieren la guerra, pero ellos mismos saben, si quieren vencer, que tal preferencia no la podrán compartir todos (cfr. Todorov, 2003).

Cassirer había propuesto ampliar la determinación tradicional del hombre que lo ve como animal racional, para definirlo mejor como animal simbólico. Ahora es Otto Bolnow quien también pide asignarle un sentido más profundo a la razón y que, en lugar de tomarla como una facultad para la desmesura, lo sea para la mesura. De esta suerte el hombre, tradicionalmente definido como un ser caracterizado por poseer la razón, es redefinido como "el ser capaz de medida, como ser que sujeta la desmesura a una medida dada por él mismo" (Bolnow, 1984, p. 21). Ambas propuestas, la de Cassirer y la de Bolnow, resultan complementarias y nos ayudan a comprender que el mundo simbólico de la cultura es la medida que el hombre adopta para sí mismo, para mantener en sus límites las fuerzas destructivas que él abriga y, de ese modo, también para darle forma a órdenes de vida mejores, porque con la disciplina de la medida se obtiene la humanidad.

\section{Vigencia de los ideales humanistas}

En un sentido muy parecido, para Sloterdijk el humanismo es lucha entre las tendencias bestializantes y las domesticadoras que constituyen el hombre (cfr. Sloterdijk, 2006). En ese conflicto se echa mano de mecanismos inhibidores de los poderes y fuerzas destructivas que, como señalamos, sin duda el ser humano posee. El psicoanálisis vio la cultura como la disputa contra el tánatos o la pulsión de muerte que intenta destruir lo vivo. Para el caso de las comunidades humanas el impulso de destruir la unidad pareciera acompañar a cada individuo con sus intereses egoístas, pero como es imposible hacernos humanos 
sin los demás, entonces, a cambio de no hacerlo, en lugar del conflicto es mejor defender ideales como la amistad y la convivencia pacífica. En todo caso son ideales entendidos como "disposiciones reales" que es preciso cultivar, y no como "deberes" impuestos.

La discordia es constitutiva de la condición humana y la paz no termina con ella. Sin embargo, el hecho de comenzar a hablar sobre esa posibilidad, con efectos prácticos en la reducción de la violencia, ya es caminar hacia ideales humanistas, sobre todo para que la muerte y la destrucción dejen de ser los espectáculos mediáticos con los que hoy, en el mundo de los medios, se alimentan a diario nuestros sueños.

Eso que los romanos eruditos llamaron "humanitas", sería impensable sin la exigencia de abstenerse de consumir la cultura de masas en los teatros de la brutalidad. Si alguna vez hasta el propio humanista se pierde por error entre la multitud vociferante, ello sólo sirve para constatar que también él es un ser humano y, en consecuencia, puede verse infectado por el embrutecimiento. Retorna el humanista entonces del teatro a casa, avergonzado por su involuntaria participación en las contagiosas sensaciones, y casi está tentado de reconocer que nada humano le es ajeno. Pero con ello quiere decir que lo humano consiste en elegir para el desarrollo de la propia naturaleza los medios inhibidores y renunciar a los desinhibidores. El sentido de dicha elección de medios reside en desacostumbrarse de la posible brutalidad propia y guardar las distancias con la escalada de deshumanización de la jauría vociferante del teatro. (Sloterdijk, 2006, pp. 34-35).

Freud sabía que el hombre es un ser entre cuyas disposiciones instintivas tiene una buena dosis de agresividad, y no se trata de "una criatura tierna y necesitada de amor" (Freud, 1981, p. 3046). el humanista, además, es consciente de todo el mal que el hombre puede causarle al hombre, sobre todo cuando se cree responsable de imponer a los demás "deberes" ideales, a cambio de "ideales" humanos. Y no se trata

... de pesimismo, sino que el hombre es, como hemos visto, un ser indeterminado en el plano moral. Necesitand o constantemente de los otros para afirmar su propia existencia, puede contribuir tanto a su felicidad como a su desagracia y poseyendo un margen de libertad en sus decisiones, se hace, por lo tanto, responsable del bien y del mal que causa. Es por eso que los humanistas están interesados en la educación: si los hombres fueran completamente buenos (o malos), no tendría sentido educarlos. (Todorov, 2003, pp. 166-167).

Tampoco es cosa de adoctrinarlos, porque es el camino que escogieron los salvadores de la humanidad
- quienes se dice son los protectores de la dignidad humana-, que desde todos los extremos han sido precisamente los causantes de enormes desgracias a individuos y pueblos.

Por otro lado, existe una visión ingenua de humanismo, según la cual los hombres son buenos y formidables, e incluso capaces de tolerar con el mayor estoicismo las peores ofensas de los demás. 0 que en nombre del humanismo, la contención de nuestros impulsos agresivos se logra con la tolerancia, pero mientras mi creencia y mi verdad no sean tocadas. Es la tolerancia de la indiferencia ofensiva, y de acopio de paciencia para soportar que exista entre nosotros alguien que no profese las mismas creencias o idearios nuestros. Por ello, en lugar de la tolerancia, el verdadero límite que podemos poner a la desmesura propia y ajena es el respeto, entendido como "consideración y miramiento".

El origen del término respeto, según Antonio Escohotado (cfr., 1998, p. 99), se remonta "al afecto que inspira el lugar donde crecimos, y funda el arraigo local de los seres humanos"; otra fuente es la atracción ejercida por el resto del mundo, que aviva un sentimiento de unidad supralocal y cosmopolita. Desde nuestro pueblo el respeto se manifiesta como amistad y buena vecindad, y desde nuestra condición humana, como habitantes del planeta o vecinos universales, el respeto se expresa como humanitas, 'humanidad'.

Como dijo una vez el poeta Jean Paul, los libros son voluminosas cartas para los amigos. Con esta frase estaba llamando por su nombre, [de modo refinado y elegante], a lo que constituye la esencia y función del humanismo: humanismo es telecomunicación fundadora de amistades por medio del lenguaje escrito. Eso que desde la época de Cicerón venimos denominando 'humanitas' es, tanto en su sentido más estricto como en el más amplio una de las consecuencias de la alfabetización. (Sloterdijk, 2006, p. 19).

Por eso, el término humanismo está estrechamente vinculado a educación y se relaciona siempre con las letras, pero, como advertimos antes, no con las letras como objeto de estudio, sino como el medio en el que se transmiten mundos o visiones del mundo, vidas de personajes reales o ficticios; experiencias nuevas que enriquecen las nuestras y ofrecen otras formas de ordenar nuestras vidas.

La educación debe tener como función preparar al hombre para que retorne a casa, a la casa de su ser, que no es un lugar seguro y fijo, lleno de creencias, principios o verdades únicas, inamovibles y absolutas. Si la educación asumiera así su función, comprendería que la casa del ser humano es la intemperie, es 
el riesgo de la lucha en la existencia por hacerse a modos de ser nobles, con miras a lo cual es preciso escuchar lo que la tradición le dice en sus obras de arte, en sus instituciones y en la filosofía o atender el nuevo saber de la ciencia, pero todo ello sobre todo con el fin de hacerse a ideales de vida agradable y grata con los demás y para comprender y juzgar mejor los asuntos humanos y no solo para ampliar el conocimiento y dominio del mundo.

La educación ofrece la oportunidad de invitar a quienes permanecen absortos en reinos donde existe un solo dios, o una única verdad o principio, a que regresen a la tierra como el ámbito propio de donde provienen como mortales que son. No podemos olvidar que también de todos sus rincones brotan pueblos con distintas formas de ser, de sentir y de expresarse que le ofrecen al hombre, para fortuna suya, muchas miradas sobre el mundo - que entre los griegos eran simbolizadas por los dioses- y enseñan que se puede ser humano de muchas maneras; además, que nuestras costumbres o formas de vida no tienen nada de natural, pues las de otras regiones son muy distintas. Por ello igualmente, en la tierra de los hombres "nadie es menos, ni más que nadie", porque la pluralidad, la diferencia y la más completa diversidad de individuos y culturas es su mejor paisaje nativo.

Volver a casa es aprender que si bien un componente de nuestra condición lo constituyen la discordia y la violencia, es preciso temerles y enfrentarlas con otros impulsos también nuestros, de cooperación, de solidaridad y de concordia, además de proteger las instituciones que nos ayuden a someterlas. Si humanismo es hacer uso de la razón como facultad de los límites, con el fin de contener las fuerzas destructivas y bestiales que van con nosotros, es para morar "los órdenes de la convivencia humana" (Bolnow, 1984, p. 13) que fundan los lugares donde encontramos refugio cada vez que retornamos de la lucha diaria por la existencia, cuando tenemos que hacer frente a la hostilidad de la vida en procura de nuestros propósitos, o a la ferocidad y la barbarie de quienes aún no le han puesto límites a su desmesura. Por todo ello, educar para vivir en paz es soñar también con que el día de mañana, sin esperar el incierto día de la emancipación total o del acuerdo definitivo, los guerreros comiencen a regresar a casa y todavía encuentren a quien abrazar.

\section{Conclusión}

Las presentes reflexiones están fundamentadas en el hecho de que la educación basada en principios y, para decirlo en términos repetidos hasta el cansancio, en información e instrucción, no corresponde a la propuesta de una educación que mantenga vivos los ideales humanistas. Por eso mismo solo podemos indicar la necesidad de establecer una política pública de educación cuyo núcleo central sea la vida humana, individual y colectiva, con vistas a conseguir lo que en términos clásicos se conoce como "la vida buena", la cual a la vez implica, en términos contemporáneos, formar "ciudadanos del mundo" (cfr. Nussbaum, 2005).

La educación basada en principios es una educación dogmática justamente porque presenta valores, puntos de vista, datos y hechos ya establecidos como la fuente del conocimiento y la acción, y desalienta la reflexión crítica. Destinada a fortalecer la especialización y las destrezas laborales, se basa en la trasmisión de información e instrucciones que atan la acción a funciones eficientes. Nadie duda de que este tipo de educación, el tradicionalmente impartido en nuestro país, reporta beneficios en el progreso material; pero a la vez, no se refleja en un mejoramiento de nuestras condiciones de convivencia, en el cuidado del entorno natural y social, en la contención efectiva de la violencia, o en el fortalecimiento de la democracia concebida en sentido socrático como "un juicio meditado sobre el bien general" (Nussbaum, 2005, p. 49), en lugar de estar movida, como hasta ahora la nuestra, por el choque entre intereses de personas y grupos.

Lo anterior significa la necesidad de pensar en otro tipo de educación cuya orientación central sea "el cultivo de la humanidad", deliberante y reflexiva, destinada a formar ciudadanos libres. Vale decir, dueños de su propio pensamiento, con vocación crítica de las opiniones, los actos y decisiones que no favorezcan el bien común y las mejores condiciones de convivencia ciudadana. Y el maestro ocupa un lugar central en este propósito formativo por su presencia personal influyente desde cuando el ciudadano es niño hasta cuando es profesional. Por ello, a cambio de "principios", basados en la autoridad, requiere proveerse de "criterios", pautas de acción y pensamiento que le hagan tomar conciencia plena de por qué es importante formar en el cultivo de la humanidad.

La reflexión que se hace en el presente trabajo busca aportar a esa toma de conciencia de maestros y alumnos, convencidos además del gran valor formativo que tiene hacer genealogía de las ideas que defendemos y de que solamente el saber que se incorpora, argumentada y conscientemente, a nuestro propio modo de ser nos otorga la capacidad de generar cambios de fondo y permanentes en el espíritu de nuestros ciudadanos.

Todo ello será posible si enseñamos a cada uno desde niño defender con argumentos sus derechos 
y puntos de vista; que sentirse diferente de otros no conduce a la discriminación sino al reconocimiento de lo diferente para enriquecer nuestra propia experiencia del mundo. Vale decir, se trata de no olvidar que existen puntos de vista plurales y muy diferentes a los nuestros, por lo que estamos obligados a conocer con claridad sus razones para someterlas a deliberación y juicio, quizás para incorporarlas a las nuestras por valiosas o para descartarlas porque estamos en capacidad de ofrecer razones más poderosas para ello. Todo ello nos ha de conducir a la necesidad de tomar decisiones curriculares que apelen al pensamiento más que a los medios (convertidos hoy en fines de la educación); vale decir, currículos centrados en la formación del hábito de la lectura, en la enseñanza reflexiva (pensamiento crítico), en aprender a pensar por uno mismo y en el respeto más que en la tolerancia.

El fondo de todo lo dicho lo sostiene una idea presente en la orientación humanista: la vida humana constituye el núcleo de la cultura, en virtud del cual adquiere sentido todo lo que hacemos como individuos y comunidad. Las ciencias, las artes y las técnicas valen en la medida en que favorezcan la vida del hombre en la tierra, y la vida de la tierra misma, pero no como sucede hoy cuando trabajan en beneficio de poderosos intereses económicos. Por eso es crucial pensar en una educación convencida de mantener vigentes los ideales humanistas y que, al mismo tiempo, conduzca al fortalecimiento de una democracia deliberativa, de pensamiento libre y abierto, con la solidez suficiente para ser sostenida por ciudadanos autónomos y no manipulables, frente a los embates de poderosos intereses que aprovechan una débil formación crítica y reflexiva para acentuar únicamente la educación centrada en la eficiencia y la productividad. El cultivo de la humanidad también incide de manera directa en proteger todos los mecanismos de convivencia pacífica porque el bienestar, la sensación de "estar bien", la alegría de compartir, de tranquilidad y de solidaridad generan en el ánimo un placer propio derivado de los bienes deseables por sí mismos. Esto ya constituye una poderosa contención -razonable, autónoma- de nuestros impulsos bárbaros, en beneficio de reconocer al otro como fuente de soporte y bienestar y no de conflicto y competencia. Para llegar a esta última conclusión es preciso comprender que los seres humanos "somos iguales" únicamente en nuestras capacidades de pensar y sentir, pero todos somos "diferentes" en la manera como las ejercemos; somos distintos en cuanto a las oportunidades que tenemos, a la rapidez o lentitud con que aprendemos, a la mayor o menor intensidad como expresamos nuestros sentimientos, etc., razón por la cual la educación no puede perder de vista las diferencias individuales y entre sociedades, la heterogeneidad de las regiones y culturas. Ello seguramente llevará a entender mejor por qué no se trata de instaurar y establecer principios fijos, ni de sobrevalorar la información, sino de favorecer las condiciones para el libre despliegue de nuestras "capacidades" de acción y pensamiento y aportar criterios para juzgar con libertad lo que es mejor para todos.

\section{Referencias}

Aristóteles. (1997). Ética nicomaquea. Madrid: GredosPlaneta DeAgostini.

Bergson, H. (1963). La evolución creadora. En Obras escogidas. México: Aguilar. Biblioteca Premios Nobel.

Bolnow, O. (1984). Antropología filosófica. Revista Educación, 30, 7-23.

Bolnow, 0. (2001). Introducción a la filosofía del conocimiento. La comprensión previa y experiencia de lo nuevo. Buenos Aires: Amorrortu.

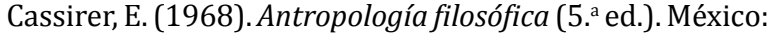
Fondo de Cultura Económica.

Della Mirandola, P. (2006). Discurso sobre la dignidad del hombre. Medellín: Editorial Pi (Ensayos para Pensar).

Escohotado, A. (1998). Tolerancia o respeto. En M. Cruz (ed). Tolerancia o barbarie. Barcelona: Gedisa.

Freud, S. (1981). El malestar en la cultura. En Obras completas. Tomo III (4. ${ }^{\mathrm{a}}$ ed.). Madrid: Biblioteca Nueva.

Nussbaum, M. (2005). El cultivo de la humanidad. Una defensa clásica de la reforma de la educación liberal. Barcelona: Paidós.

Platón. (1998). República. Barcelona: Gredos-Planeta DeAgostini.

Safranski, R. (2010). El mal o el drama de la libertad (2. ed.). Barcelona: Tusquets (Fábula).

Safranski, R. (2013). ¿Cuánta verdad necesita el hombre? Buenos Aires: Tusquets.

Sloterdijk, P. (2006). 4ed. Normas para el parque humano. Madrid: Siruela.

Sófocles. (2006). Antígona. En Tragedias. Barcelona: Gredos.

Todorov, T. (2003). Deberes y delicias. Una vida entre fronteras. Buenos Aires: Fondo de Cultura Económica.

Weber, M. (1995). El político y el científico. Barcelona: Altaya. 
Thy

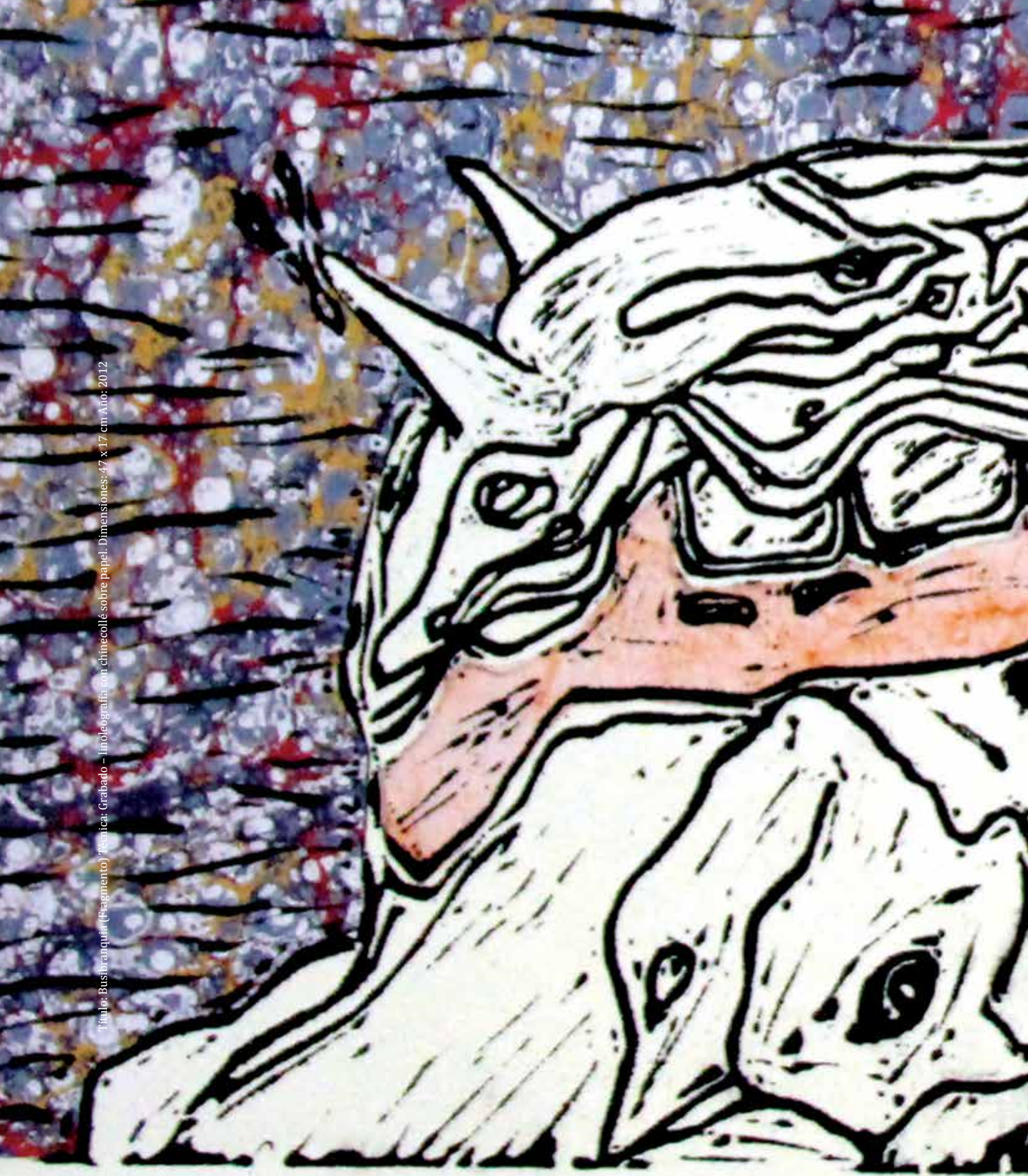

